\title{
ANALYSIS OF IGNITION RISK ON MECHANICAL EQUIPMENT IN ATEX
}

\author{
Claire Petitfrère \\ INERIS \\ Parc Alata BP 2 \\ F-60550 Verneuil en Halatte \\ France
}

\author{
Christophe Proust \\ INERIS \\ Parc Alata BP 2 \\ F-60550 Verneuil en Halatte \\ France
}

\begin{abstract}
Until the implementation of the ATEX directive $94 / 9 / C E$, the certification of equipment intended to explosive atmospheres was only dedicated to electrical equipment. Since the 1st July 2003, the non-electrical sources of inflammation are also to be looked at before putting an ATEX equipment on the market (pumps, couplers, reducing gears, ...).

Among these sources, mechanical friction and impacts are a main cause of ignition of explosive atmosphere. The risk analysis of the equipment consists in considering the failures, which can lead to ignition. If the failure involves a friction between two parts or an impact, we shall estimate if this friction or impact dissipates a sufficient amount of energy to ignite the surrounding explosive atmosphere.

As part of the European program MECHEX, we have studied the process of degradation of the mechanical energy into heat during friction and impacts and we have examined the mechanisms of ignition at the contact zone.

An extensive experimental program is presented and some "simple" modelling is proposed on purpose of practical applications. For frictional situations, a critical rubbing power is calculated without any limitations as for a potential lower boundary concerning the rubbing velocity. For "impacts", the relevant parameter for ignition is not the kinetic energy of the projectile but its velocity and the nature of the materials.
\end{abstract}

Index Terms - ATEX, Mechanical ignition source, Nonelectrical Equipment

\section{INTRODUCTION}

Since the implementation of the ATEX directive 94/9/CE [1] in July 2003, the non-electrical sources of inflammation shall also be examined before putting an ATEX equipment on the market (pumps, couplers, reducing gears, ...).

European harmonized standards have been developed by CEN/TC 305 WG2 to give requirements for non-electrical equipment. The basic standard for non-electrical equipment is the EN 13463-1 [2], which requires an ignition hazard assessment of the equipment

Concerning mechanical equipment, this assessment often underlines the possibility of mechanical friction or impacts as an ignition source during foreseeable or rare malfunction. When such a source appears, the manufacturer shall estimate if the friction or impact dissipates a sufficient amount of energy to ignite the surrounding explosive atmosphere.

The European program MECHEX was dedicated to the study of the process of ignition during friction and impact.
In the first part of this paper, the actual requirements for mechanical equipment are given. The main results concerning the ignition by friction and impact are presented in the second part and some practical implications in the last section

\section{REQUIREMENTS AND HAZARD ASSESSMENT}

\section{A. Requirements of Directives and Standards}

Non electrical equipment are dealt with in directive 94/9/CE when placed on the market for use in hazardous areas (concerns firstly the supplier) and by directive 1999/92/CE [3] when intended to be installed in hazardous area (concerns firstly the user).

The essential health and safety requirements of the directive 94/9/CE demand among others that the manufacturer take measures to prevent the ignition of explosive atmospheres, taking into account the nature of every electrical and nonelectrical sources of ignition. Some supplementary requirements are specific of the category of equipment :

- For category 1 (equipment intended to zone 0) :

Equipment must be so designed and constructed that sources of ignition do not so become active, even in the event of rare malfunctions.

- $\quad$ For category 2 (equipment intended to zone 1)

Equipment must be so designed and constructed as to prevent ignition sources arising, even in the event of frequently occurring disturbances or equipment operating faults, which normally have to be taken into account.

- $\quad$ For category 3 (equipment intended to zone 2) :

Equipment must be so designed and constructed as to prevent foreseeable ignition sources which can occur during normal operation.

The directive 1999/92/CE demands that:

- The employer shall ensure that a document, called 'explosion protection document', is drawn up and kept up to date. This document shall contain the demonstration that work equipment is designed, operated and maintained with due regard for safety.

- Work equipment for use in hazardous area which was made available in the undertaking or establishment for the first time after 30 June 2003 shall comply with the directive 94/9/CE (with the category adapted to the zone).

- Work equipment for use in hazardous area which was already in use or was made available in the undertaking 
or establishment for the first time before 30 June 2003 shall comply from that date with the minimum requirements laid down in Annex II, Part A. So all necessary measures must be taken to ensure that the work equipment have been designed, constructed assembled and installed, and are maintained and operated, in such a way as to minimize the risks of an explosion.

To comply with the requirements of the Directive 94/9/CE we may generally use the harmonized standard EN13463-1. We can also use the frame of this standard to carry the hazard assessment of the equipment that is already installed and to include this assessment to the explosion protection document demanded by the directive 1999/92/CE.

The standard EN 13463-1 is based on the assessment of the ignition hazards of equipment depending on the category of this equipment. It can be used as a stand-alone standard but for mechanical equipment the standard EN 13463-5 [4] is generally used in addition. This standard defines the protection concept "constructional safety" with marking "c". The principle of this type of protection is to apply constructional measures so as to protect against the possibility of ignition from hot surfaces, sparks and adiabatic compression generated by moving parts. The requirements are based on good engineering principles, so that risk of mechanical failures likely to create incendive temperatures or sparks, are reduced to a very low level.

\section{B. Ignition Hazard Assessment}

The ignition hazard assessment consists in reviewing all potential ignition sources of the equipment and in distinguishing normal operation, expected malfunction and rare malfunction. Then will be considered the measures applied to prevent each source becoming effective.

Concerning mechanical equipment with moving parts the hazard assessment will often underline the risk of friction or impact as an expected or rare malfunction. That could be the case for instance for pumps when there is no more fluid and where parts could enter in contact in rare malfunction. We can also think to the bearings or to the friction of a roller on a rail.

When the malfunction introducing a risk or friction or impact is identified, the problem is then to determine if this friction or impact could become an effective ignition source or not. The type of source could then be a hot surface or sparks but it is difficult to know if the phenomena are sufficient to ignite the explosive atmosphere.

\section{MECHANICAL FRICTION AND IMPACT}

\section{A. IGNITION RISK BY FRICTION}

Friction between two solid bodies is a process through which mechanical energy is transformed into heat. Experience reveals that heat is produced in the rubbing zone where the material is severely stretched and diffuses outwards. It is well known that the amount of heat evolved is in proportion of the applied force and sliding speed [6].

Further, if the friction is sufficiently intense, some material may be torn away resulting in fragments being expelled. This event is sometimes called "friction sparks" or "spark shower".

\section{Experimental equipment}

For a given heat power produced in the rubbing zone [7], traditional thermodynamical laws tell that the maximum temperature may depend on some geometrical sizes (area of the contact zone, diameter of the machine,...) of the rubbing equipment. Mainly for this reason, two experimental set-ups have been used (figure 1). The configuration of a fixed slider rubbing onto a rotating wheel has been selected because a rather precise control of the rubbing parameter is amenable.

The larger device [8] is a $30 \mathrm{~cm}$ diameter wheel, $22 \mathrm{~mm}$ thickness rubbing against a $40 \mathrm{~mm}$ high, $25 \times 25 \mathrm{~mm}$ square cross section slider for most tests. The sliding velocity can be adjusted between 0.2 and $20 \mathrm{~m} / \mathrm{s}$ and the normal load between 0 and $5000 \mathrm{~N}$.

The smaller device is a $10 \mathrm{~cm}$ wheel, $8 \mathrm{~mm}$ thick rubbing against a $15 \mathrm{~mm}$ high, $7 \times 7 \mathrm{~mm}$ square cross section slider. The sliding velocity can be adjusted between 0.05 and $15.7 \mathrm{~m} / \mathrm{s}$ and the normal load between 0.2 and $1000 \mathrm{~N}$. Temperatures have been measured by optical methods and thermocouples. During the tests, the normal load, friction coefficient and speed were controlled $[5,8,10]$.
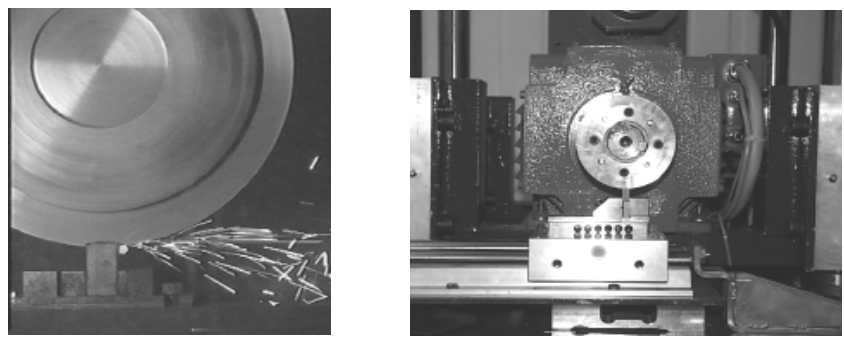

Figure 1 : rubbing experimental set-ups (Large scale $30 \mathrm{~cm}$ dia. wheel- left and small scale $10 \mathrm{~cm}$ dia. wheel-right)

The evolution of the rubbing temperature as function of the nominal power expressed in terms of normal load $(\mathrm{N})$ times the sliding velocity $(\mathrm{V})$ is shown on figure 2 for the various sliders used and the two machines. There is a clear trend of increasing the rubbing temperature as function of the nominal power. There is also a clear incidence of the nature and of the width of the slider and globally of the size of the rubbing machine. 


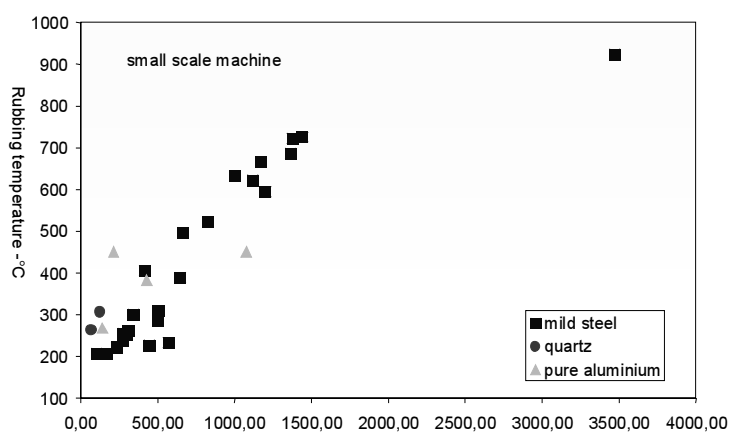
N.V (W)
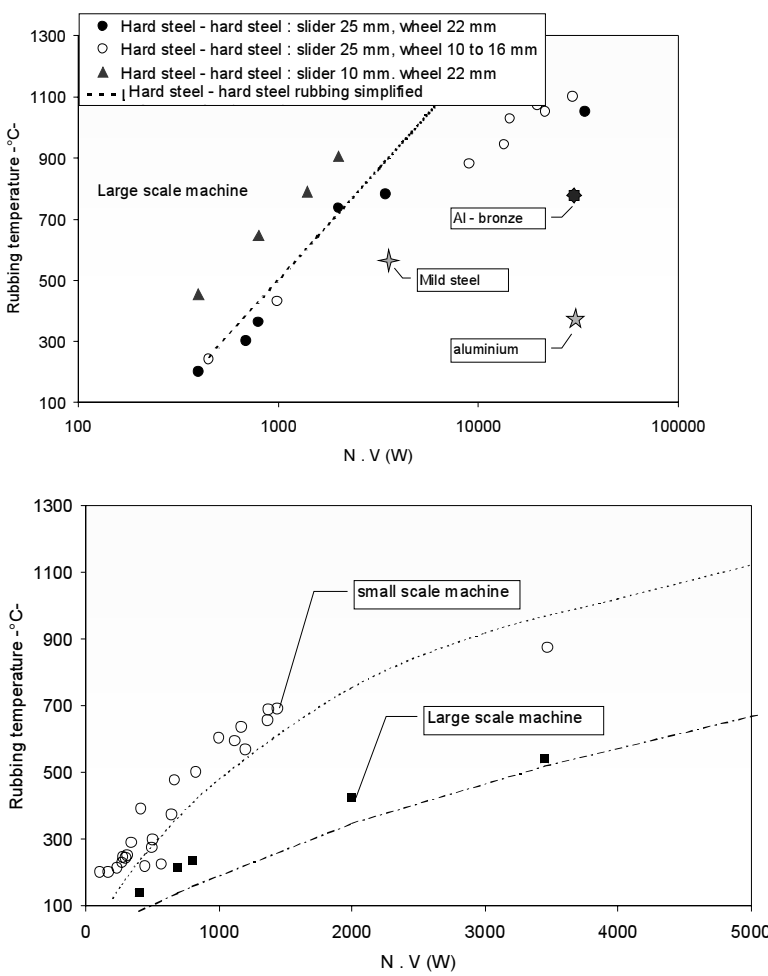

Figure 2: Rubbing temperature as function of N.V for various sliders and the two machines (on the top, only with the small scale equipment, in the middle, only with the large scale equipment and on the bottom graph a comparison of the results with the two machines with a hard steel - mild steel rubbing configuration)

In some tests, flying fragments (sparks material) have been collected in order to evaluate the size of them and the wear rate. For steel rubbing against steel at a few $\mathrm{m} / \mathrm{s}$, the typical particle size seems of the order of a few hundred of $\mathrm{mm}$ and the wear rate, extremely dependent on the experimental conditions, is better scaled in $\mathrm{mm}^{3} / \mathrm{s}$ [5].

\section{Mechanisms of ignition}

The analysis reveals that ignition during friction and impacts may result from three different processes [7] :

- In direct contact with the hot rubbing zone whenever the local temperature is large enough according to the mechanism of the hot plate [9]. The experimental investigation and some theoretical evidence shows that the critical parameter is the temperature of the hot zone, of the order of hundreds of ${ }^{\circ} \mathrm{C}$;

- The power dissipated in friction may easily be of the order hundreds of Watts. If the friction is occurring in a sufficiently confined area, the mean temperature of the ATEX may rise and reach the autoignition point. This situation should well be represented by the standard ignition temperatures ;

- The sparks may be a cause of ignition. However, since the initial temperature at the beginning of the flight should not be different from that of the rubbing zone, the sparks are likely to constitute a preferential cause of ignition only if, later in their flight, their temperature increases well above that of the rubbing zone. This may occur if the flying particles are able to burn. In this case, the ignition process may be linked to the spark ignition mechanism referring to minimum ignition energies.

\section{Ignition around the heated surface}

This ignition mechanism is believed to be the main cause for mechanical ignition $[8,12]$ often invoked but, to our knowledge, never really proven.

For friction, experiments performed with the large scale rubbing machine used in explosive atmospheres and filmed with high speed video [8] demonstrate clearly that ignition proceeds at the rubbing zone. It occurs as soon as some critical temperature threshold has been reached at the rubbing zone. These temperatures have been estimated for a number of atmospheres (hydrogen-air, methane-air, propane-air, ethylene-air, diethyl-ether-air, acetone-air,...) and compared to critical temperatures determined previously [9] for hot surface ignition in explosive atmospheres ( $T_{\text {pcrit }}$ ). It has been realized that both sets of values correlate extremely well demonstrating that "frictional" ignition is a "hot surface" ignition mechanism. It has been however noted that the critical hot surface temperature does not seem to correlate so well with the standard autoignition temperature nor better with the minimum ignition energy [5], indicating that this might be a new type of ignition criterion.

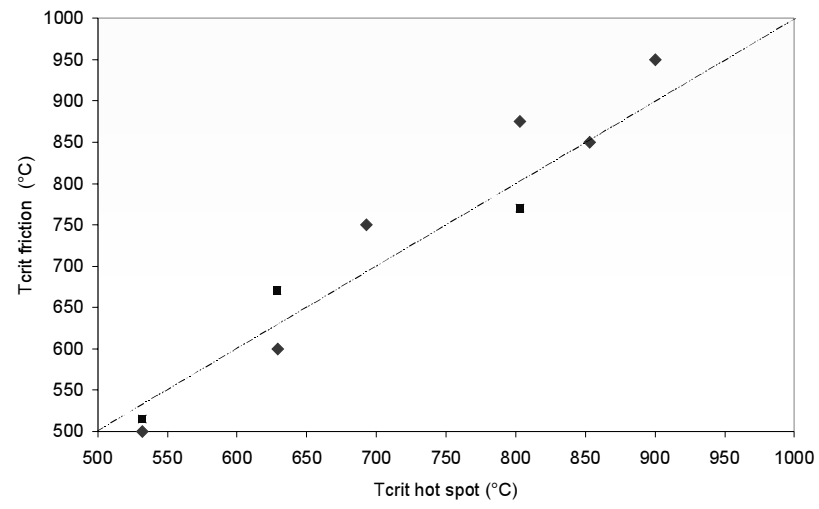

Figure 3 : tabulated critical hot surface ignition temperature and observed contact temperature upon ignition during friction 


\section{Volumetric ignition}

Experiments on the small scale rubbing machine with steel_steel configurationhave shown only a moderate increase of the average temperature throughout a volume in closing the wheel $\left(40^{\circ} \mathrm{C}\right)$ and inside the spark shower as compared to the temperature reached at the rubbing zone $\left(700^{\circ} \mathrm{C}\right)$. So the ignition should occur most probably at at the hot contact zone before any possibility of ignition throughout volume could arise [5]

\section{Sparks}

There was no evidence of any ignition to be undoubtedly attributable to a flying spark in the present experiments [5]. There was even no evidence of any fragment to burn in the surrounding atmosphere even in the extreme situation of aluminum rubbing intensively against hard steel. Is it to be said that only the situation of a light alloy rubbing against some rusty material and leading to "thermite reactions" [12] is to be considered for "spark" ignition during friction ?

To help and clarify this important point, explosive atmospheres were submitted to a small chemically inert and artificially heated object, simulating a fragment [5]. Globally, the required temperature to produce ignition is well above the critical "hot surface" temperatures apart from the specific case of sulphur, which need to be further analysed. Thus, it is confirmed that the "spark" temperature need to be well above those of the rubbing zone to generate an increased risk of ignition suggesting that the fragments have to burn somehow.

\section{Modelling}

These findings have been analyzed and collapsed into a reasonable model [4]. It is postulated that ignition would occur at the hottest point, in the immediate vicinity of the rubbing zone (we thus leave apart the special case of "thermite " reaction). Following, the ignition parameter is the critical hot surface temperature defined before, depending on the nature of the atmosphere. We then have to derive the contact temperature from the frictional process and compare it to the former. The standard Coulomb-Joule relationship has been used to calculate how much heat is produced in the friction, This amount of heat is driven out from the contact zone by thermal conduction and is modeled as a local heat source onto an semi-infinite solid [10]. The final equation reads:

$$
q=f \cdot N \cdot V=\frac{4}{\pi} \cdot\left(\lambda_{1}+\lambda_{2}\right) \cdot \frac{A}{R} \cdot\left(T_{f}-T_{a m b}\right)
$$

where

- $T_{f}$ : temperature of the rubbing zone

- $T_{a m b}$ : ambient temperature (boundary temperature of the bodies)

- $\mathrm{R}$ : radius of contact area

- A : contact area

- $\lambda_{\mathrm{i}}$ : heat conductivity of body $i$ in the rubbing zone

- $f$ : friction coefficient

- $\quad \mathrm{N}$ : normal load
- $V$ : rubbing velocity

- $q$ : heat dissipated in friction

For the practical use of this expression within the frame of explosion safety, the following aspects need to be considered:

- a proper choice of the critical ignition temperature must be made. For explosive atmospheres, the relevant parameter would be $T_{\text {pcrit }}$ which is above but not directly related to the standard ignition temperature ;

- the area of the contact zone depends on the geometry of the device and may be found with a detailed analysis of the system. It should not be smaller than the ratio of the normal load to the Brinell Hardness which gives a lower boundary for $\mathrm{R}$;

- the critical power dissipated in rubbing ( $q=f . N . V)$ is the part lost in the friction which, in normal operation, is usually a very low fraction of the nominal power, typically a few percent for friction coefficients of the order of 0.001 to 0.01 . Only in case of severe malfunction (a shaft broken, a fused bearing...), the friction power may reach the nominal power with a fraction coefficient between 0.1 and 1. .

Some comparison between this simplified method and experimental data is shown on figure 4 . Here, the rubbing situation typically corresponds to a severe malfunction as defined above with a friction coefficient equated to unity. The model gives a lower estimate of the critical power but is reasonable in trends and order of magnitude.

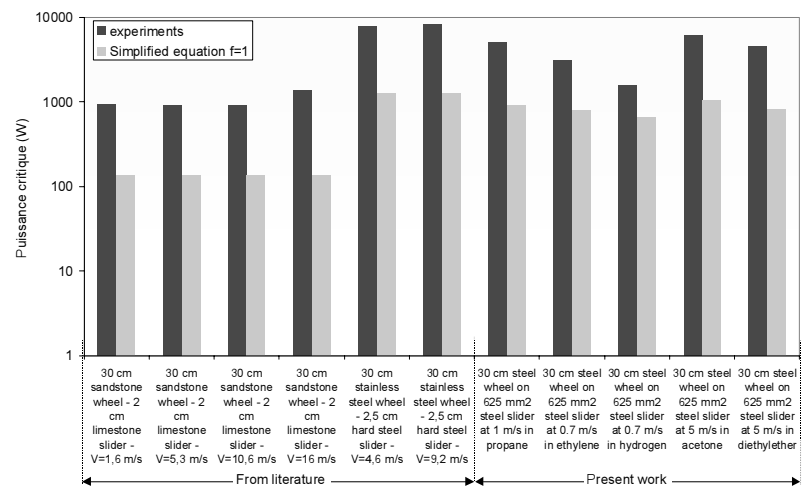

Figure 4 : performances of the simplified model for frictional ignition against existing data [7] and results issued from the present program

This physical analysis implies that the maximum temperature in the rubbing zone depends only on the friction power without any limitations about any lower boundary about the rubbing velocity. For instance, it has been possible to ignite propane-air, ethylene-air and hydrogen-air mixtures at rubbing velocities equal to or even smaller than $1 \mathrm{~m} / \mathrm{s}$, which has been sometimes given a "safe" limit [10]. 


\section{B. IGNITION RISK BY IMPACT}

\section{Experimental equipment}

The experimental facility consists of a free fall vertical device. The target is a strong mild steel plate $(5 \mathrm{~mm} \times 70$ $\mathrm{cm} \times 45 \mathrm{~cm}$ ) anchored on a rigid thick wood plate $(11 \mathrm{~cm})$ impeding flexion during impact. The plate is inclined to favor a glancing blow. In most experiments the angle of $60^{\circ}$ has been chosen. The projectile (diameter $18 \mathrm{~mm}$ of steel, aluminium, copper,...) is propelled by an air cannon on a precise point of the target at variable velocity between 5 to $50 \mathrm{~m} / \mathrm{s}$.

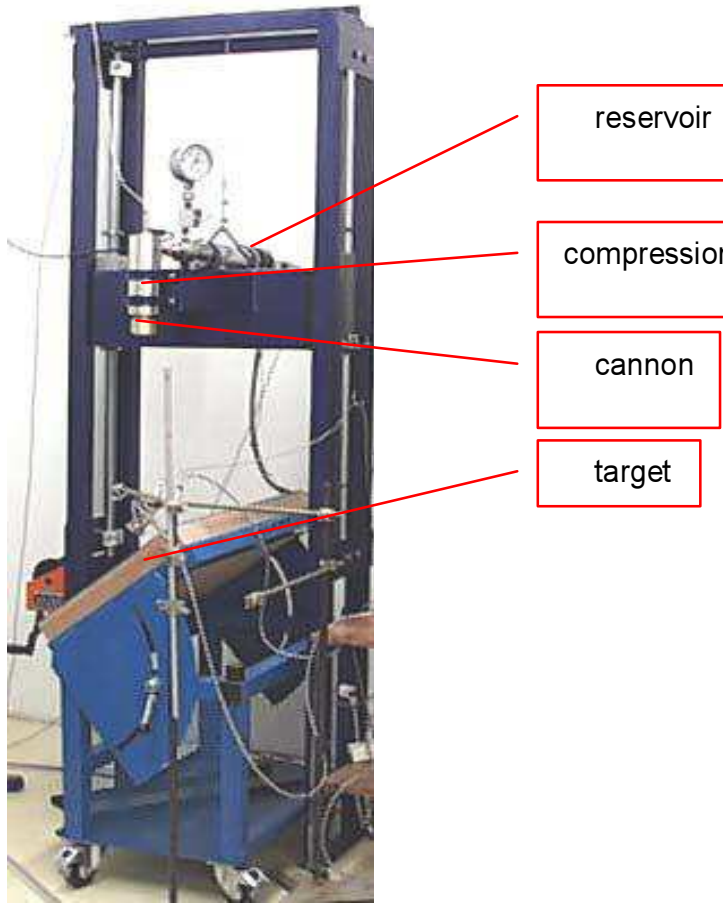

Figure 5 : Experimental impact test equipment

The impact was filmed with a high speed camera in order to estimate the impact speed and to detect the fragments Simultaneously, the temperature in the contact zone was measured with a high speed monochromatic pyrometer $[5,7]$

A sample of those measurements is shown on figure 6. The impact results in a sharp temperature rise (up to hundreds of ${ }^{\circ} \mathrm{C}$ in a few tens of microseconds) followed from a rapid but more progressive decrease (in milliseconds). Usually a chip is produced which constitutes a unique fragment of $\mathrm{mm}$ size

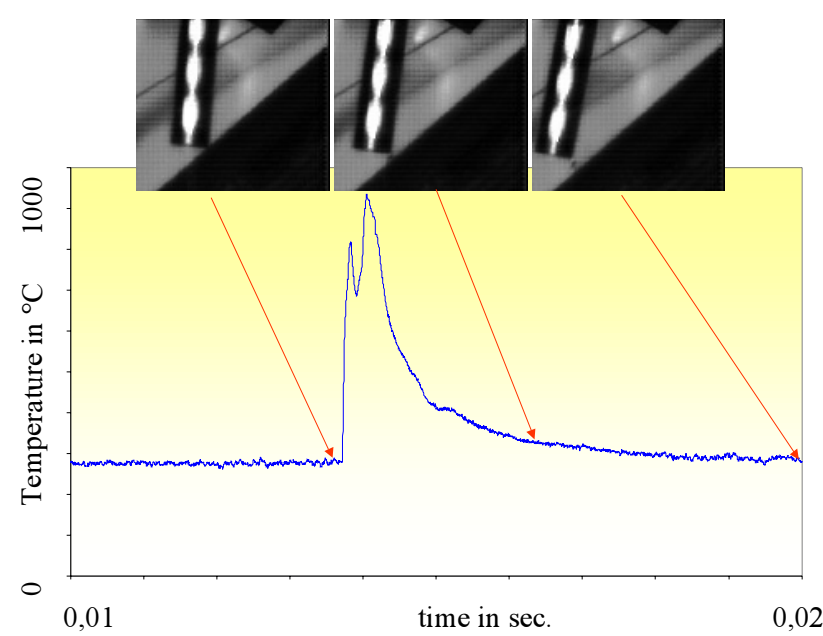

Figure 6: typical temperature reading and excepts from the high speed film (18 $\mathrm{mm}$ steel rod of $20 \mathrm{~cm}$ long, impacting at $10 \mathrm{~m} / \mathrm{s}$ )

Some data are shown on figure 7 for various experimental nditions. The impact temperature depends primarily upon the impact velocity and nature of the material and only very weakly on the size of the projectile. A further analysis of the same data shows that the impact temperature is not correlated to the incident kinetic energy [5]

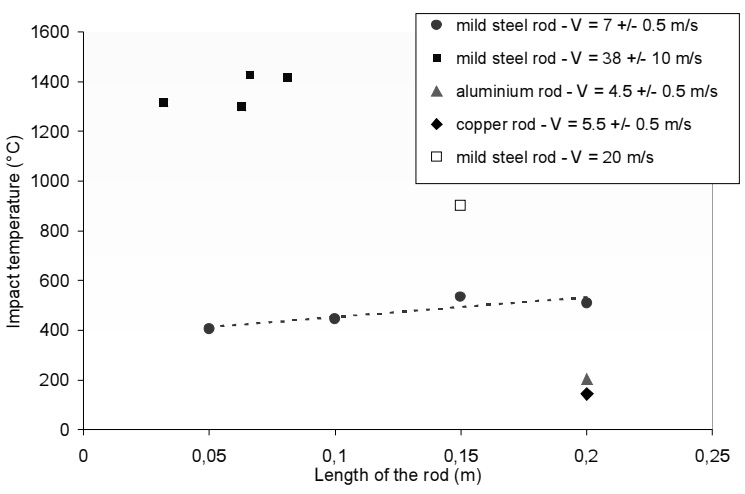

Figure 7 : Maximum impact temperature of the hot spot for various conditions

The physical analysis of the results $[5,7]$ suggests that the efforts, deformations, fragment production... should be the consequence of the strain waves produced in the very first moments of the impact and propagated at the speed of sound in the materials. These waves are responsible for the rebound. The experimental evidence suggests also that heat is produced due to some intense but very short rubbing on the target during the time of the rebound. while the projectile slides against the target with the tangential component of the impact velocity. The amount of heat produced is then driven away by transient thermal conduction $A$ model has been proposed elsewhere [5] and the final equation reads: 


$$
\left(T_{i m p}-T_{a m b}\right)=f \cdot K_{m} \cdot V^{2} \cdot \sqrt{L}
$$

where $L$ stands for the length of the projectile and $V$ the impact velocity. $T_{\text {imp }}$ is the peak temperature reached during the impact. $\mathrm{K}_{\mathrm{m}}$ is a composite parameter dependant only on the intrinsic properties of the bodies like sound speeds, specific masses and heat capacities, thermal conductivity $\mathrm{K}_{\mathrm{m}}$ is typically of the order of 10 (20 for steel) in SI units.

About ignition, both the fragment, if any, and the hot spot may contribute to ignition equally because of their similar size. It has been found also [5], that the ignition process is closer to a hot spot mechanism as described before than to the standard spark ignition mechanism. Because of the short duration of the hot spot during an impact, the critical ignition temperature appears larger, by a factor between 1 to 2 depending on the atmosphere.

For the practical use of the preceding expression, a friction coefficient of 1 may be selected. $\sqrt{ } \mathrm{L}$ may easily vary in more

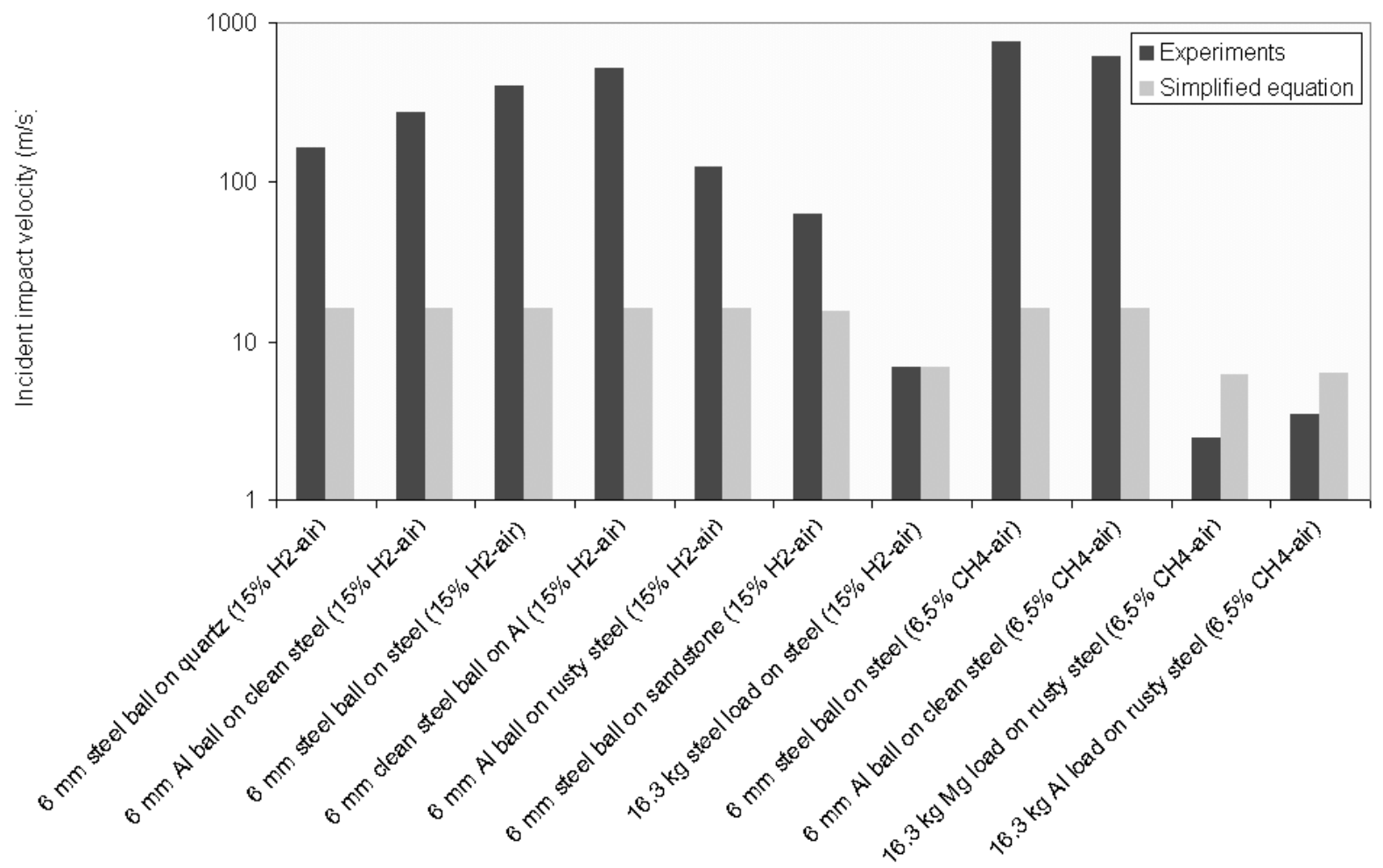

Figure 8: performances of the simplified model for impact ignition against existing data

The comparison is less favorable than for friction but impact ignition tests are difficult to perform because of a rather poor reproducibility. Nevertheless, this very simplified approach seems conservative apart from the specific situations of "thermite" reactions or large objects, mostly because, we believe, the exact geometry of the projectile is not precisely known.

As a final remark, the kinetic energy of the projectile does not appear, at any moment, neither in the data reduction of the than a ratio of 10 whereas $T_{\text {pcrit }}$ varies only in a ratio of 2 . It is then tempting to use this formula by setting $\mathrm{K}_{m}$ to 20 , a rather large value, and $\mathrm{T}_{\text {imp }}$ to $550^{\circ} \mathrm{C}$, one of the smallest practical ignition temperature, $L$ being the remaining unique variable equal to the largest dimension of the projectile. It is finally very simple to find an order of magnitude of a critical impact velocity, capable of igniting an explosive atmosphere. A comparison with data from the literature [7] is presented in figure 8 . experiments nor in the theoretical approach as Rasuo [11] noticed earlier The velocity of the impact appears as a more convenient parameter.

\section{PRACTICAL IMPLICATIONS}

The foregoing simplified models are issued from a more sophisticated tool in which the various equations are solved 
numerically. The latter gives less conservative results than the

former with exactly the same trend [5]. Both can be used for practical applications.

The basic parameters to feed into the models are the nature of involved material, the size of the equipment, the explosive properties of the atmosphere, the velocity (sliding velocity for friction and incident velocity for impact), the normal load and frictional area for friction. The temperature in the contact zone is calculated and compared to the critical hot spot temperature for the atmosphere.

Some examples of applications are presented below.

\section{A. Lifting screw}

Within the scope of the CE certification, the case of a lifting screw devoted to the transfer of combustible powders was studied. The screw is a long helical steel wire turning inside a steel sleeve (inner diameter of the sleeve is about $150 \mathrm{~mm}, 10$ $\mathrm{mm}$ wire diameter). The device is driven by a $5500 \mathrm{~W}$ electrical engine at $1500 \mathrm{rpm}$. Hazard assessment reveals a risk of friction of the wire against the sleeve. The explosive dusty atmosphere has a standard ignition temperature of $240^{\circ} \mathrm{C}$ suggesting a critical hot spot ignition temperature of about $700^{\circ} \mathrm{C}[9]$

With a thermal conductivity of steel of the order of $15 \mathrm{~W} . \mathrm{m} / \mathrm{K}$ and a rubbing size of the order of $10 \mathrm{~mm}$ (diameter of the wire), the critical temperature could be reached for a frictional power as low as $400 \mathrm{~W}$ according to the simplified friction model presented above. This finding may be compared with the experimental data of figure 2 if we consider that this lifting screw is somewhat comparable to the experimental rubbing machines in size. At $700{ }^{\circ} \mathrm{C}$, the friction coefficient is about 0.3 so that N.V for the lifting screw should be about $1500 \mathrm{~W}$, in line with the data obtained with the small scale machine.

Although rather indicative, this result suggests that the power of the machine is larger enough to generate immediately a dangerous situation in case of steel-steel friction. The simultaneous presence of a dust atmosphere inside the sleeve should then be avoided by ensuring that the device is always full with bulk dust at full power for instance.

\section{B. Turbine}

We have examined a turbine with a mobile part in aluminium and an envelope in alloy of steel-aluminium.

The diameter of the wheel was $340 \mathrm{~mm}$. The nominal speed was of $3500 \mathrm{tr} \cdot \mathrm{min}^{-1}$ and the peripherical speed was of $62 \mathrm{~m} / \mathrm{s}$.

We have considered the case of a piece of alloy steelaluminium blocked between the rotor and the casing of the turbine generating a strength of $3,6 \mathrm{~N}$.

The use of the foregoing simplified expressions reveals that the rubbing temperature at the contact point will be about $416^{\circ} \mathrm{C}$, which can be compared to the critical ignition hot spot temperature of an explosive atmosphere. In the practical studied case it has been demonstrated that there was non ignition risk.

\section{C-Gasoline feeder}

A gasoline pump supplier is concerned by the explosion hazard raised by a new type of connector to feed LPG in cars. The possibilities of an impact of the connector on some solid surface and of a friction due to the rubbing along a moving vehicle were identified. Impact and rubbing experiments have been performed. Both the connector and the rubbing/impact surfaces are mainly made of steel. The typical diameter of the connector is $5 \mathrm{~cm}$. Given the geometry of the connector, a typical rubbing size of $10 \mathrm{~mm}$ was chosen.

For LPG, the critical ignition hot spot temperature is about $650^{\circ} \mathrm{C}$. At this level of temperature, the steel-steel friction coefficient is about 0.3 .

The use of the foregoing simplified expressions reveals that the critical impact velocity would be of the order of $23 \mathrm{~m} / \mathrm{s}$ and the critical rubbing power of about $800 \mathrm{~W}$ (N.V = $800 / 0.3=2500 \mathrm{~W}$ ). Experiments have shown that the peak impact temperature is about $630^{\circ} \mathrm{C}$ at $28 \mathrm{~m} / \mathrm{s}$ and the rubbing temperature is close to $300^{\circ} \mathrm{C}$ with a rubbing power of $400 \mathrm{~W}$ $(\mathrm{N} . \mathrm{V}=1200 \mathrm{~W})$. Recalling that the rubbing temperature has been observed to be approximately proportional to N.V, the experimental observations seem coherent with the predictions.

On the practical side, those values seem high with regard to the normal way of operating the device and the considered risk might only appear in case of rare events.

\section{CONCLUSION}

Since the implementation of the ATEX directive 94/9/CE in July 2003 , the non-electrical sources of inflammation shall also be examined before putting an ATEX equipment on the market (pumps, couplers, reducing gears, ...).

European harmonized standards have been developed by CEN/TC 305 WG2 to give requirements for non-electrical equipment. The basic standard for non-electrical equipment is the EN 13463-1, which requires an ignition hazard assessment of the equipment with the list of all potential ignition sources. Depending on the category of the equipment $(1,2$ or 3$)$, inducing the area where it can be installed (zone $0,1,3$ or 20 $21,22)$, the assessment has to be carried considering only normal use or also foreseeable or rare malfunction. The same work can be done to ensure that the equipment already in use fulfills the requirements of the directive 1999/92/CE and can be described in the explosion protection document.

Concerning mechanical equipment, this assessment often underline the possibility of mechanical friction or impacts as an ignition source during foreseeable or rare malfunction. When such a source appears, the manufacturer shall estimate if the friction or impact emits a sufficient energy to ignite the surrounding explosive atmosphere.

The European program MECHEX has permitted to study the process of ignition during friction and impact. The process of degradation of the mechanical energy into heat during friction or impacts and the mechanisms of ignition at the contact zone have been studied.

An extensive experimental program is presented in this paper but many points have only been surveyed. It was found that 
apart for the very special situation of "thermite" reactions, which has not been investigated in this program, the "sparks shower" resulting from the production of fragments in the contact zone is less dangerous than the high temperature of the friction or impact area. It has been noted that the critical parameter is the temperature of the hot surface, a property of the mixture, which does not seem to be closely linked to any known standard ignition parameters.

Some "simple" modeling is proposed on purpose of practical applications. For frictional situations, a critical rubbing power is calculated without any limitations about any lower boundary concerning the rubbing velocity. For instance, it has been possible to ignite propane-air, ethylene-air and hydrogen-air mixtures at rubbing velocities equal to or even smaller than 1 $\mathrm{m} / \mathrm{s}$, which has been sometimes unduly given a "safe" limit. The main variable is the friction coefficient the prediction of which is not easy: it varies from 0.001 to 1 depending on the lubrication and materials.

For "impacts", the relevant parameter for ignition is not the kinetic energy of the projectile but its velocity and the nature of the materials. The experimental data are not sufficiency to valid the model and more experiences need to be lead.

As practical implications, some results of MECHEX have already been taken into account in the redaction of the second edition of EN 13463-1. Some limited couples of parameter speed/torque of rubbing have been introduced instead of the only speed limit of $1 \mathrm{~m} / \mathrm{s}$ which was given in the EN 13463-5.

We have presented in this paper some practical cases where the simplified model has been used. The materials in contact, the considered atmosphere, the speed and torque shall be known. The surface of contact is estimated and the model calculates the temperature of rubbing or impact zone and compares it to the critical ignition temperature of the explosive atmosphere. It may help for the hazard assessment.

On the other hand a certain time is necessary to reach the maximum temperature at the rubbing surface and some equipment may use this parameter for implementing a detection of the failure that will induce the rubbing.

The model should still be tested on other practical case. Some complementary studies would be necessary to determine the time to reach maximal temperature by rubbing.

It would also be interesting to have a better knowledge of the value of the critical ignition temperature as a new data for the different explosive atmospheres as it seems not to be correlated with the known data of autoignition temperature (AIT) and minimal ignition energy (MIE).

\section{ACKNOWLEDGEMENTS}

The authors are grateful to European communities with supported the MECHEX project between 2001 and 2005. They thank also the others sponsors like HSE, the German authorities, the French ministry for research and the French ministry of industry. A warm congratulation to the colleagues throughout Europe who took an active part to the project: $S$ Hawksworth (coordinator), M. Beyer, D. Lakic, R. Rogers, D; Raveau, X. Lefebvre, V. Pina and P. Hervé

\section{REFERENCES}

[1] Directive 94/9/EC of the European Parliament and the Council of 23 March 1994 on the approximation of the laws of the Member States concerning equipment and protective systems intended for use in potentially explosive atmospheres, Official Journal no. L100, 199404-19, 1-29.

[2] EN 13463-1 : 2001, Non-electrical equipment for potentially explosive atmospheres - Part 1 : Basic method and requirements.

[3] Directive 1999/92/EC of the European Parliament and of the Council of 16 December 1999 on minimum requirements for improving the safety and health protection of workers potentially at risk from explosive atmospheres, Official Journal no L23/57, 2000-01-28

[4] EN 13463-5: 2003, Non-electrical equipment for potentially explosive atmospheres - Part 5: Protection by constructional safety "C".

[5] C. PROUST, S. HAWSKWORTH, R. ROGERS, M. BEYER, D. LAKIC, D. RAVEAU, P. HERVE, V. PINA, C. PETITFRERE, $X$. LEFEBVRE, "Development of a method for predicting the ignition of explosive atmospheres by mechanical friction and impacts (MECHEX)," HPMIE, Halifax, 2006.

[6] KRAGELSKII I.V. (1965), Friction and Wear, Butterworths, London

[7] PROUST C., RAVEAU D., 2004, « Toward modelling of frictional ignition Loss prevention and safety promotion in the process industries ", Proceedings of the 11th International Symposium, 31 May - 3 June 2004, Praha, Czech Republic

[8] HAWKSWORTH S., ROGERS R., PROUST Ch., BEYER M., SCHENCK S., GUMMER J., RAVEAU D. (2004a), "Mechanical ignition hazards in potentially explosive atmospheres - EC project MECHEX", communication to the international ESMG symposium, Nürnberg, Germany, 16th-18th of March 2004

[9] CARLETON $F$, BOTHE $H$., PROUST Ch., HAWKSWORTH'S. (2000), "Prenormative Research on the Use of Optics in Potentially Explosive Atmospheres », Final Report, European Contract SMT4-CT96-2104

[10] HAWKSWORTH S., ROGERS R., PROUST Ch., BEYER M., SCHENCK S., GUMMER J., RAVEAU D. (2005), "Ignition of explosive atmospheres by mechanical equipment », I.Chem. Symp. Series 150

[11] RASUO V., ZIVKOVIC R. (1990), « Development of device and method for testing of mechanical sparks which might ignite explosive mixtures », HSE translation $n^{\circ} 13471$

[12] POWELL F. (1969), « Ignition of gases and vapors », Industrial and Engineering Chemistry, vol. 61, pp. 29-37 


\section{VITA}

Dipl. Ing. Claire Petitfrere leads a certification team concerning equipment intended to explosive atmospheres in INERIS since 2002. She is a member of standardisation group WG2 from TC305 dealing with standards for non electrical equipment in explosive atmospheres.

Dr. Christophe PROUST, is a senior scientist specialised in explosions and has managed the work of INERIS in MECHEX project. 